Check for updates

Cite this: RSC Adv., 2018, 8, 31658

\title{
A FRET-based fluorescent and colorimetric probe for the specific detection of picric acid $\dagger$
}

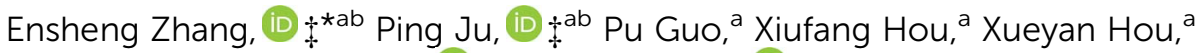 \\ Haiming $\mathrm{Lv}^{\mathrm{a}}{ }^{\mathrm{j}} \mathrm{Ji}$-jiang Wang ${ }^{\mathrm{D}}{ }^{\mathrm{a}}$ and Yuqi Zhang $\left(\mathbb{D}{ }^{* a}\right.$
}

Picric acid (PA) as an environmental pollutant and high explosive, has recently received considerable attention. In this paper, a novel fluorescent and colorimetric chemo-probe (L) for the highly selective and sensitive detection of picric acid has been revealed. The probe was facilely constructed using rhodamine B, ethylenediamine and 4-(9H-carbazol-9-yl)benzoyl chloride. Significant fluorescence changes based on an intramolecular fluorescence resonance energy transfer (FRET) effect followed by a distinct color change from colorless to pink were observed after addition of picric acid to the probe solution. Selectivity measurements revealed that the as-synthesized probe exhibited high selectivity toward PA in the presence or absence of other analytes. The experimental titration results suggested that the as-synthesized probe is an effective tool for detection of PA with a nanomolar scale detection limit (820 nM) and could also serve as a "naked-eye" indicator for PA detection.

Received 26th June 2018

Accepted 4th September 2018

DOI: $10.1039 / \mathrm{c} 8 \mathrm{ra05468a}$

rsc.li/rsc-advances

real-time monitoring limit their practical applications.

\section{Introduction}

Picric acid (PA), a typical water soluble polynitroaromatic compound, has been widely used in the manufacture of rocket fuels, ${ }^{1}$ fireworks, ${ }^{2}$ matches, ${ }^{3}$ dyes, ${ }^{4}$ medicines and pesticides. ${ }^{5}$ Its heavy use has caused severe environmental pollution $^{6}$ and public health issues, ${ }^{7}$ such as headaches, weakness, anemia and liver injury. Another important concern regarding picric acid is its high explosive detonation properties and low safety coefficient, which might be used for terrorist attacks. ${ }^{7}$ Hence, there is an urgent need for convenient and specific analytical methods for the detection of picric acid. Especially, a high selectivity "naked-eye" probe is highly desirable.

Currently, various universal analytical techniques and platforms such as high performance liquid chromatography (HPLC), ${ }^{8}$ Raman spectroscopy, ${ }^{9}$ ion-mobility spectroscopy $(\mathrm{IMS})^{10}$ and electrochemical methods ${ }^{11}$ etc., have been established for the detection of nitrogen containing aromatic (NCAs) explosives including picric acid. Although remarkable progress has been made for the above mentioned methods, some drawbacks such as high cost, less selectivity and lack of

${ }^{a}$ Laboratory of New Energy \& New Function Materials, Shaanxi Key Laboratory of Chemical Reaction Engineering, College of Chemistry and Chemical Engineering, Yan'an University, Yan'an, Shaanxi, 716000, P. R. China. E-mail: yqzhang@iccas. ac.cn; sdzes2006@163.com

${ }^{b}$ College of Chemistry and Chemical Engineering, Qufu Normal University, Qufu, Shandong, 273165, P. R. China

$\dagger$ Electronic supplementary information (ESI) available. See DOI: 10.1039/c8ra05468a

¥ Ensheng Zhang and Ping Ju equally contributed to this work.
Luckily, fluorescence and colorimetric sensors ${ }^{12,13}$ has emerged as a promising analysis technique in recent years and various novel materials have been designed and synthesized. For example, functional small organic molecules, ${ }^{14-23}$ metal or nonmetal nanoparticles, ${ }^{24,25}$ metal organic frameworks (MOFs), ${ }^{26-31}$ etc. However, the fluorescence "turnon" type and "naked-eye" sensors are still highly desirable for simple, sensitive, and selective detection of PA.

In this work, we report a fluorescent-colorimetric molecular probe $\mathbf{L}$ (Scheme 1) for the highly selective and sensitive detection of picric acid. The probe was facilely synthesized using rhodamine $\mathrm{B}$, ethylenediamine and $4-(9 \mathrm{H}$-carbazol9-yl)benzoyl chloride. Distinct color change and rapid "turn-on" fluorescence were observed when treated $\mathbf{L}$ with picric acid, which revealed its potential application as a "naked-eye" and fluorescent indicator for picric acid. Furthermore, several advantages such as ready availability of the starting materials, efficient synthetic routes and nanomolar level ( $820 \mathrm{nM})$ detection limitation make this probe an useful chemosensor for PA detection.

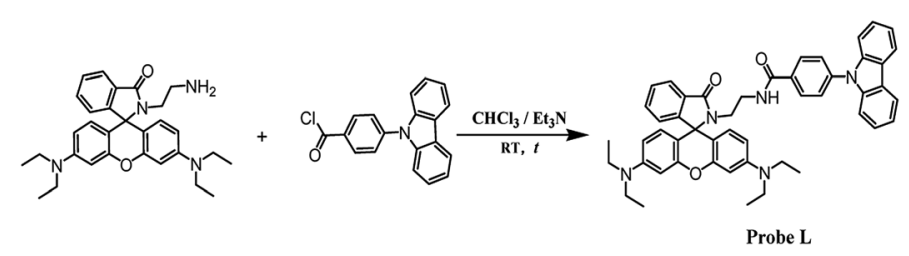

Scheme 1 The synthetic route of probe $L$. 


\section{Experimental sections}

\subsection{Instruments and reagents}

${ }^{1} \mathrm{H}$ NMR measurement were performed on Bruker AVII-400 MHz $\left({ }^{1} \mathrm{H}\right.$ NMR, $\left.400 \mathrm{MHz}\right)$ and OXFORD AS-500 $500 \mathrm{MHz}\left({ }^{1} \mathrm{H}\right.$ NMR 500 $\mathrm{MHz},{ }^{13} \mathrm{C}$ NMR $125 \mathrm{MHz}$ ) spectrometers using DMSO- $d_{6}, \mathrm{CD}_{3} \mathrm{Cl}$, and $\mathrm{CD}_{3} \mathrm{OD}$ as the solvents at $298 \mathrm{~K}$. The chemical shifts were reported in parts per million (ppm). MS spectra were recorded on a Waters Micromass Quattro Micro API LC-MS in electrospray ionization mode and HRMS spectrum was measured on a LC-Q-TOF (ESI) apparatus. The FT-IR spectra were measured on a Shimadzu IR Affinity-1S FT-IR Spectrophotometer using the $\mathrm{KBr}$ pellet. Fluorescence spectra were recorded on an Agilent Cary Eclipse fluorescence spectrophotometer and the excitation wavelength is $314 \mathrm{~nm}$ (with excitation slit of $2.5 \mathrm{~nm}$ and emission slit of $5.0 \mathrm{~nm}$ ) or $500 \mathrm{~nm}$ (with excitation slit of $2.5 \mathrm{~nm}$ and emission slit of $5.0 \mathrm{~nm}$ ) at room temperature. Absorption spectra were monitored on a Shimadzu UV-2550 spectrophotometer.

The 4-(9H-carbazol-9-yl)benzoyl chloride was synthesized from 4-(9H-carbazol-9-yl)benzoic acid and thionyl chloride (ESI, Part $\mathrm{I} \dagger$ ). The $N$-(rhodamine-B)lactam-ethylenediamine was synthesized according to the reported methods (ESI, Scheme $\mathrm{S} 2 \dagger)$ and purified by recrystallization from anhydrous ethanol. The other chemical reagents were purchased from commercial suppliers and used without further purification.

The stock solutions of $p$-nitrophenol ( $p$-NP), $o$-nitrodiphenol (o-NP), 4-methylphenol (4 MP), $p$-dihydroxybenzene ( $p$-DHB), $p$ nitrobenzoic acid ( $p$-NBA), 5-aminoisophthalic acid (5-AIPA), $p$ hydroxybenzoic acid ( $p$-HBA), $p$-nitrophenylhydrazine ( $p$-NPH), 2,4-dinitrophenylhydrazine (2,4-DNPH), phenylhydrazine (PH) and $m$-nitroaniline ( $m$-NA), 2,4,6-trinitrotoluene (TNT, $4.4 \mathrm{mM}$ in methanol) were prepared in anhydrous ethanol at the concentration of $10 \mathrm{mM}$. The concentration of the probe (L) stock solutions was $200 \mu \mathrm{M}$ in anhydrous ethanol and diluted to $20 \mu \mathrm{M}$ before used in the titration experiments.

Warning! Picric acid is highly explosive and should be handled carefully in small quantities.

\subsection{Synthesis of the probe (L)}

The purified $N$-(rhodamine-B)lactam-ethylenediamine $(484 \mathrm{mg}$, $1.0 \mathrm{mmol}$ ) and triethylamine $(2 \mathrm{~mL})$ were dissolved in dry chloroform $(5 \mathrm{~mL})$ and then added to a three-necked flask. 4(9H-carbazol-9-yl)benzoyl chloride $(336 \mathrm{mg}, 1.1 \mathrm{mmol})$ in dry chloroform ( $5 \mathrm{~mL}$ ) was added dropwise to the flask over $1 \mathrm{~h}$. The resulting mixture was stirred at room temperature under nitrogen atmosphere until completion of the reaction (monitored by TLC). The mixture was filtered and the filtrate was evaporated under reduced pressure. The crude product was purified by column chromatography using EtOAc-PE $(1: 2)$ as eluent. The probe (L) was obtained as white crystal in $85 \%$ yield. mp. $103 \sim 105{ }^{\circ} \mathrm{C},{ }^{1} \mathrm{H}$ NMR $\left(500 \mathrm{MHz}, \mathrm{CD}_{3} \mathrm{Cl}\right)(T=298 \mathrm{~K}) \delta: \mathrm{ppm}$ 8.55 (s, 1H, -CONHR), 8.17 (d, $J=8.55 \mathrm{~Hz}, 2 \mathrm{H}), 8.15$ (d, $J=$ $8.10 \mathrm{~Hz}, 2 \mathrm{H}), 7.96(\mathrm{t}, J=4.30 \mathrm{~Hz}, 1 \mathrm{H}), 7.68(\mathrm{~d}, J=8.20 \mathrm{~Hz}, 2 \mathrm{H})$, $7.47(\mathrm{~d}, J=7.50 \mathrm{~Hz}, 4 \mathrm{H}), 7.43(\mathrm{t}, J=8.00 \mathrm{~Hz}, 2 \mathrm{H}), 7.31(\mathrm{t}, J=$ $7.45 \mathrm{~Hz}, 2 \mathrm{H}), 7.12(\mathrm{t}, J=4.75 \mathrm{~Hz}, 1 \mathrm{H}), 6.49(\mathrm{~d}, J=8.85 \mathrm{~Hz}, 2 \mathrm{H})$, $6.41(\mathrm{~d}, J=1.45 \mathrm{~Hz}, 2 \mathrm{H}), 6.29\left(\mathrm{dd}, J_{1}=8.85 \mathrm{~Hz}, J_{2}=1.55 \mathrm{~Hz}, 2 \mathrm{H}\right)$, $3.49\left(2 \mathrm{H}, \mathrm{NCH}_{2} \mathrm{CH}_{2} \mathrm{~N}\right), 3.34$ (q, $\left.J=6.90 \mathrm{~Hz}, 8 \mathrm{H}\right), 3.25(2 \mathrm{H}$, $\left.\mathrm{NCH}_{2} \mathrm{CH}_{2} \mathrm{~N}\right), 1.18(\mathrm{t}, J=6.90 \mathrm{~Hz}, 12 \mathrm{H}) ;{ }^{1} \mathrm{H}$ NMR $(500 \mathrm{MHz}$, $\left.\mathrm{CD}_{3} \mathrm{OD}\right)(T=298 \mathrm{~K}) \delta: \operatorname{ppm} 8.19(\mathrm{~d}, J=7.65 \mathrm{~Hz}, 2 \mathrm{H}), 8.03(\mathrm{~d}, J=$ $8.5 \mathrm{~Hz}, 2 \mathrm{H}), 7.95$ (d, $J=6.70 \mathrm{~Hz}, 1 \mathrm{H}), 7.69(\mathrm{~d}, J=8.10 \mathrm{~Hz}, 2 \mathrm{H})$, $7.55(\mathrm{~m}, 2 \mathrm{H}), 7.43(\mathrm{~m}, 4 \mathrm{H}), 7.32(\mathrm{t}, J=7.15 \mathrm{~Hz}, 2 \mathrm{H}), 7.09(\mathrm{~d}, J=$ $6.75 \mathrm{~Hz}, 1 \mathrm{H}), 6.47(\mathrm{~m}, 4 \mathrm{H}), 6.39(\mathrm{~d}, J=8.80 \mathrm{~Hz}, 2 \mathrm{H}), 3.47(\mathrm{t}, J=$ $\left.6.10 \mathrm{~Hz}, 2 \mathrm{H}, \mathrm{NCH}_{2} \mathrm{CH}_{2} \mathrm{~N}\right), 3.38(\mathrm{q}, J=6.80 \mathrm{~Hz}, 8 \mathrm{H}), 3.31(\mathrm{t}, J=$ $\left.5.95 \mathrm{~Hz}, 2 \mathrm{H}, \mathrm{NCH}_{2} \mathrm{CH}_{2} \mathrm{~N}\right), 1.18(\mathrm{t}, J=6.75 \mathrm{~Hz}, 12 \mathrm{H}) ;{ }^{13} \mathrm{C} \mathrm{NMR}$ (125 MHz, $\left.\mathrm{CD}_{3} \mathrm{OD}\right) \delta$ : ppm $169.8(\mathrm{C}=\mathrm{O}), 167.5(\mathrm{C}=\mathrm{O}), 154.0$, $153.4,149.0,140.6,140.3,132.8,132.7,130.3,128.8,128.1$, 126.2, 125.8, 123.7, 123.6, 122.2, 120.1, 120.0, 119.9, 109.3, 108.3, 104.5, 97.7, 66.0 (spiro-atom), 44.0, 39.4, 39.3, 11.5; FT-IR (KBr) $\nu_{\max } / \mathrm{cm}^{-1} 3325(\mathrm{NH}), 3054,2971,2931,1677$ (spirolactam ring $\mathrm{C}=\mathrm{O}), 1620(\mathrm{C}=\mathrm{O}), 1488,1445,1225,1121$, 759; MS (ESI) calcd for $\mathrm{C}_{49} \mathrm{H}_{48} \mathrm{~N}_{5} \mathrm{O}_{3}[\mathrm{M}+\mathrm{H}]^{+}$, found: 754.7; HRMS (ESI-TOF): $m / z[\mathrm{M}+\mathrm{H}]^{+}$calcd for $\mathrm{C}_{49} \mathrm{H}_{48} \mathrm{~N}_{5} \mathrm{O}_{3}$ : 754.3752; found: 754.3757 .

\section{Results and discussion}

\subsection{Solvent selection and response kinetics}

In order to obtain a suitable and green reaction system, the fluorescence intensity of $\mathbf{L}$ in the presence or absence of PA was studied in different solvents $\left(\lambda_{\mathrm{ex}}=500 \mathrm{~nm}, \lambda_{\mathrm{em}}=586 \mathrm{~nm}\right.$, slits: $2.5 \mathrm{~nm} / 5 \mathrm{~nm})$. As shown in Fig. 1, no-fluorescence was detected in the absence of PA in all the tested solvents. However, remarkable turn-on fluorescence enhancement was observed after the addition of PA in methanol $(\mathrm{MeOH})$ and ethanol (EtOH) solution which were more efficient hydrogen bond donors. Meanwhile, the fluorescence intensity was extremely weak in dimethyl formamide (DMF) and tetrahydrofuran (THF). Hence, ethanol was chosen as the solvent for the following fluorescent and colorimetric tests.

The fluorescence and UV-vis spectra of the probe solution (20 $\mu \mathrm{M})$ were recorded every $5 \mathrm{~min}$ after addition of PA $(200 \mu \mathrm{M})$. As depicted in Fig. S10, $\uparrow$ a new and remarkable fluorescence enhancement at the wavelength of $586 \mathrm{~nm}$ could be observed after addition of PA for $5 \mathrm{~min}$. With increasing the response time, the fluorescence intensity increased and reached the maximum after $80 \mathrm{~min}$ (Fig. 2a). Correspondingly, a new UV-vis

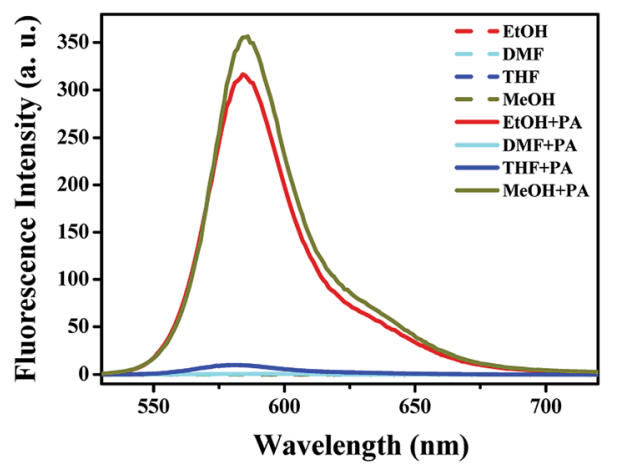

Fig. 1 Fluorescence intensity of $\mathrm{L}(20 \mu \mathrm{M})$ in the presence $(200 \mu \mathrm{M})$ or absence of PA $\left(\lambda_{\mathrm{ex}}=500 \mathrm{~nm}, \lambda_{\mathrm{em}}=586 \mathrm{~nm}\right.$, slits: $\left.2.5 \mathrm{~nm} / 5 \mathrm{~nm}\right)$ in different solvents. 

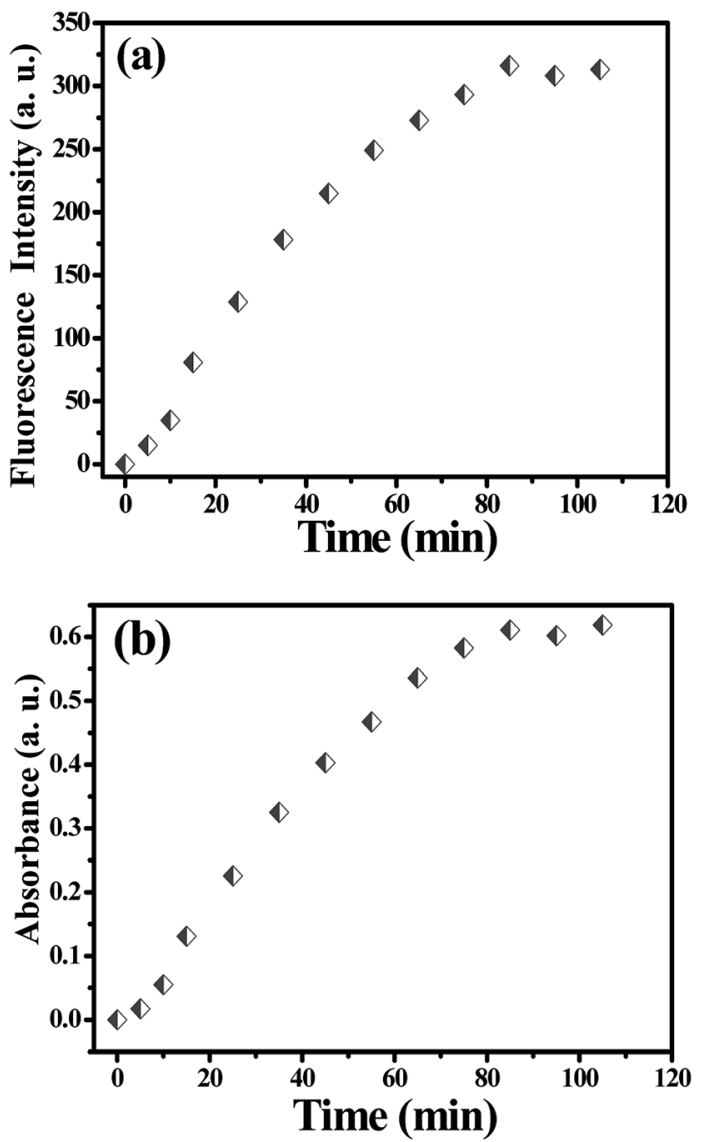

Fig. 2 (a) The fluorescence intensity $\left(\lambda_{\mathrm{em}}=586 \mathrm{~nm}\right)$ of the probe solution after addition of PA with time; (b) the absorbance $(\lambda=560 \mathrm{~nm})$ of the probe solution after addition of PA with time.

absorption band centered at $560 \mathrm{~nm}$ appeared after addition of PA for 5 min (Fig. S11†) and the absorbance intensity reached the equilibrium at $80 \mathrm{~min}$ (Fig. $2 \mathrm{~b}$ and S11†). Hence, all the fluorescence and UV-vis spectra were recorded at $80 \mathrm{~min}$ after addition of PA at room temperature. It is worth mentioning that, a recognizable color change of the probe solution from colorless (without PA) to pink (after reacted with PA) was observed together with the above mentioned process.

\subsection{Selectivity of the probe $L$}

Probe solutions $(2 \mathrm{~mL}, 20 \mu \mathrm{M})$ were treated with various phenols (4-MP, $p$-DHB, $p$-HBA) and NCAs (PA, $p$-NP, $o$-NP, $p$-NBA, 5 -AIPA, $p$-NPH, 2,4-DNPH, PH, $m$-NA and TNT) at the same concentration $(200 \mu \mathrm{M})$ for the selectivity studies. The UV-Visible absorbance spectra were shown in Fig. 3a. Obviously, a new absorption band centered at about $560 \mathrm{~nm}$ occurred only when adding PA to the solution. As recorded in the photograph (Fig. 3b), the solution color changed from colorless to pink after the addition of PA. This could be attributed to the formation of the spiro-lactam ring-opening product, which implied that the as-synthesized molecular probe $\mathbf{L}$ might be served as a "nakedeyes" probe for PA.

The selectivity of this probe was further evaluated by observing the fluorescence spectra of the probe solutions in the
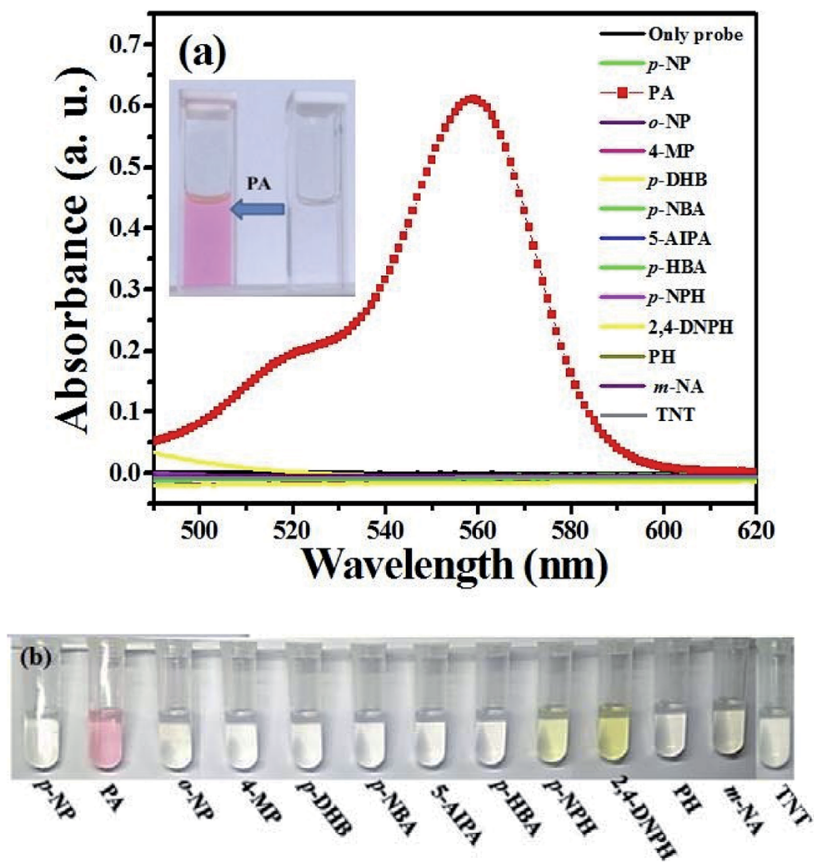

Fig. 3 (a) Absorption spectra of $L(20 \mu M)$ in the presence of various phenols $(200 \mu \mathrm{M})$ or NCAs $(200 \mu \mathrm{M})$; (b) corresponding photographs.

presence of various analytes. We chose $314 \mathrm{~nm}$ as the excitation wavelength because there was an absorbance band centred at $314 \mathrm{~nm}$ for the free probe solution, which could be attributed to the absorbance of $4-(9 H$-carbazol-9-yl)benzamide fluorophore (Fig. S12 in ESI $†$ ). For the original solution of probe $\mathbf{L}$, a fluorescence emission at the wavelength of $420 \mathrm{~nm}$ occurred (Fig. 4a) based on the emission of the 4-(9H-carbazol-9-yl) benzamide fluorophore. Interestingly, after the addition of analytes including phenols and NCAs, this emission band changed irregularly, but only PA generated a remarkable new emission band centered at $586 \mathrm{~nm}$. It can be seen that the fluorescence emission peak red-shifted from $420 \mathrm{~nm}$ to $460 \mathrm{~nm}$ and the intensity decreased in the presence of PA. Particularly, a strong fluorescence emission at $586 \mathrm{~nm}$ could be clearly observed, which resulted from the emission of the newly formed delocalized xanthane fluorophore (spiro-lactam ringopening product). Fig. $4 \mathrm{~b}$ displays the photograph of probe solutions with different analytes under $365 \mathrm{~nm}$ UV-light. A bright orange emission was observed after adding PA to the probe solution, which was obviously different from other solutions. For the compound 5-AIPA, the solution emitted bright blue fluorescence which might be due to the enhancement effect of 5-AIPA and probe (Fig. 4a).

The interference measurements were carried out by recording the fluorescence emission intensity changes $\left(\lambda_{\mathrm{em}}=\right.$ $586 \mathrm{~nm}$ ) after adding $200 \mu \mathrm{M}$ other analytes (phenols and other NCAs) to the mixture of $\mathbf{L}$ and PA ( $\mathbf{L} 20 \mu \mathrm{M}$ and PA 200 $\mu \mathrm{M}$ ). As shown in Fig. 5, no remarkable fluorescence intensity change was observed for the mixture solution (probe $20 \mu \mathrm{M}$ and PA $200 \mu \mathrm{M}$ ) before and after addition of interfering compounds $(200 \mu \mathrm{M})$. These results demonstrated that the as- 

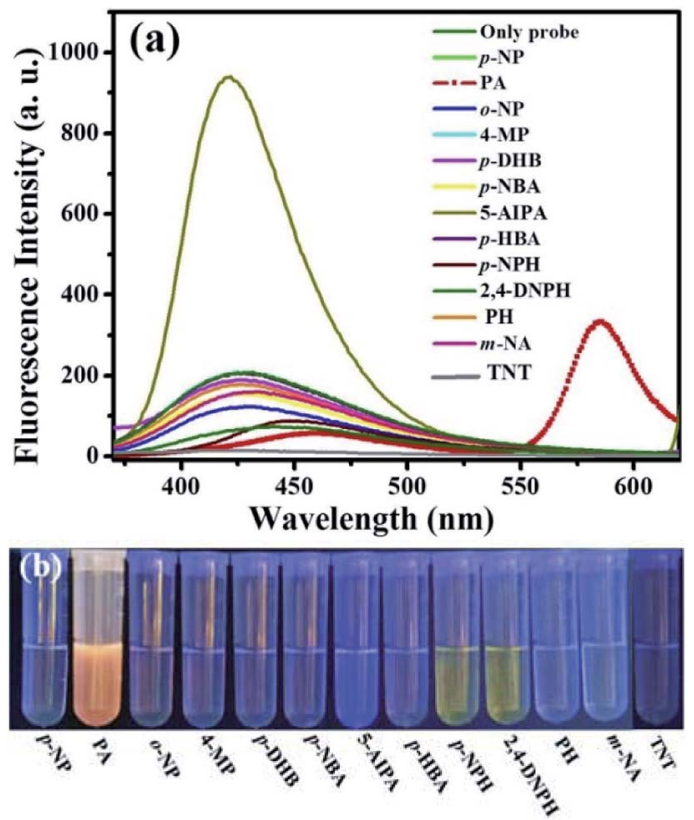

Fig. 4 (a) Fluorescence spectra of $\mathrm{L}(20 \mu \mathrm{M})$ in the absence and presence of $200 \mu \mathrm{M}$ various aromatic compounds ( $\lambda_{\text {ex }}=314 \mathrm{~nm}$, slits: $2.5 \mathrm{~nm} / 5 \mathrm{~nm}$; slits: $1.0 \mathrm{~nm} / 5 \mathrm{~nm}$ for 5 -AIPA); (b) photograph of probe solutions with different aromatic compounds under $365 \mathrm{~nm}$ UV lamp.

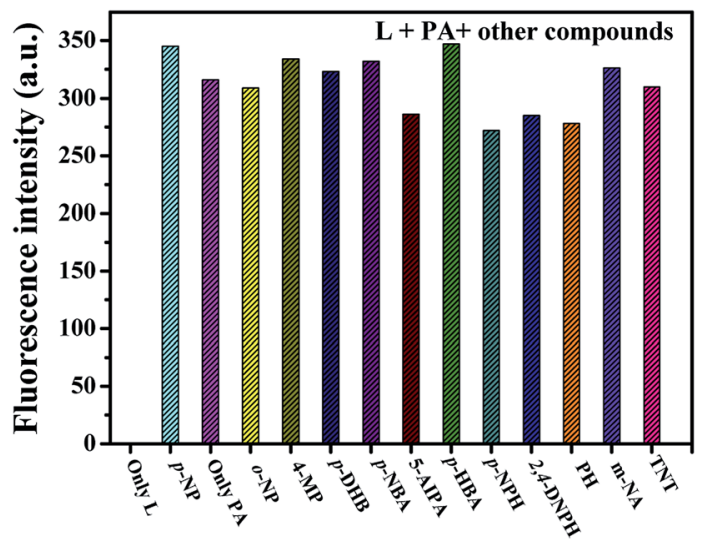

Fig. 5 Interference tests for probe $\mathrm{L}\left(\lambda_{\mathrm{ex}}=314 \mathrm{~nm}, \lambda_{\mathrm{em}}=586 \mathrm{~nm}\right.$, slits: $2.5 \mathrm{~nm} / 5 \mathrm{~nm})$.

synthesized probe $\mathbf{L}$ is highly selective towards PA and its response cannot be interfered by other compounds in ethanol solution.

\subsection{Sensitivity of probe $L$}

The sensitivity were assessed by observing the fluorescence and UV-visible spectra of probe solution $(2 \mathrm{~mL}, 20 \mu \mathrm{M})$ with different concentration of PA $(0-300 \mu \mathrm{M})$. In addition, all the fluorescence and UV-vis spectra were recorded at room temperature and the measurement system were transparent and homogeneous.

Fig. 6a (left) shows that there is no absorption band at wavelength range from 500-600 $\mathrm{nm}$ in the absence of PA and
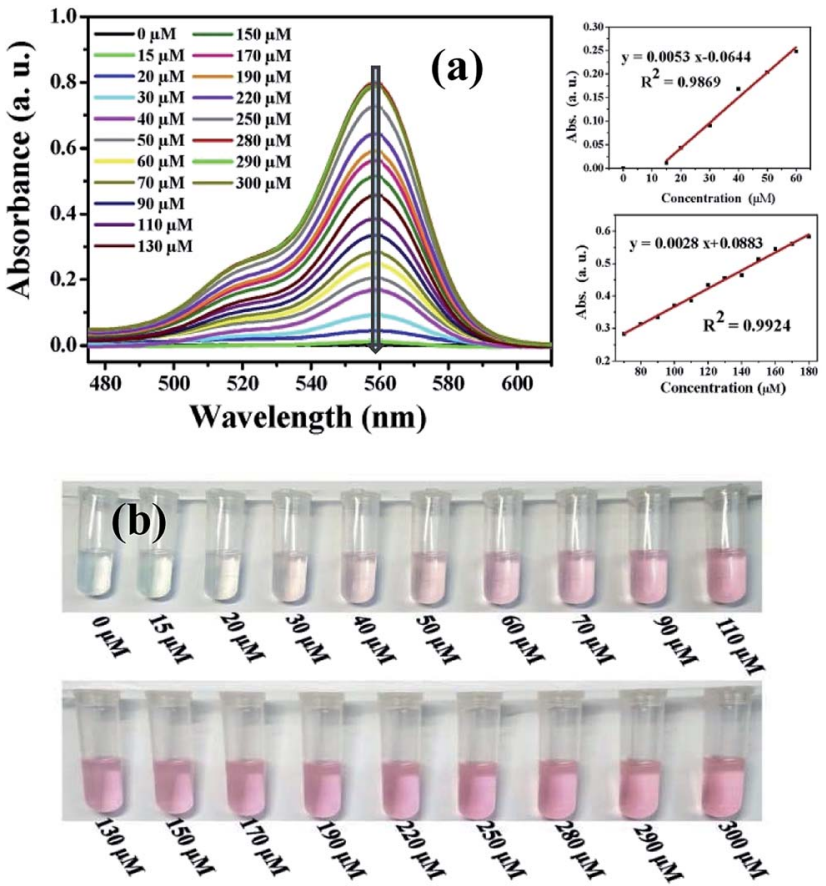

Fig. 6 (a) Absorption intensity of probe solution with various concentrations of PA (left) and linear fitting curve of the absorption intensity at $560 \mathrm{~nm}$ versus the concentration of PA (right); (b) color changes of the probe solutions with gradually addition of PA under visible light.

the probe solution is colorless (Fig. 6b). However, a new absorption band centered at $560 \mathrm{~nm}$ appeared when upon addition of $15 \mu \mathrm{M}$ PA. With increasing the concentration of PA from $15 \mu \mathrm{M}$ to $280 \mu \mathrm{M}$, the absorbance intensity at $560 \mathrm{~nm}$ steadily increased and leveled off to a constant value at $280 \mu \mathrm{M}$, accompanying with a gradual color change from colorless to pink (Fig. 6b). Linear fitting curves of the absorption intensity at $560 \mathrm{~nm}$ versus the concentration of PA were obtained, and displayed in Fig. 6a (right). Obviously, the absorbance intensity displays two good linear correlations with the concentration of PA in the range of $15-60 \mu \mathrm{M}\left(R^{2}=0.9869\right)$ and $70-180 \mu \mathrm{M}\left(R^{2}=\right.$ 0.9924). The detection limit of $\mathbf{L}$ for PA calculated according to the eq. $3 \sigma / k$ (ref. 32 and 33) was $820 \mathrm{nM}$, indicating the probe molecule is high sensitive to PA.

To further investigate the detection performance of the probe (L) towards PA, a series of fluorescence titration experiments were carried out. As shown in Fig. 7a, the fluorescence emission intensity at $420 \mathrm{~nm}$ gradually decreased and the emission peak shifted from 420 to $460 \mathrm{~nm}$ with the increasing of PA concentration. Most importantly, a new fluorescence emission band at $586 \mathrm{~nm}$ appeared after the addition of $15 \mu \mathrm{M}$ PA, and the intensity increased gradually in this process. (Photograph of probe solutions with different concentration of PA under $365 \mathrm{~nm}$ UV light was exhibited in Fig. S13 $\dagger$ ). Linear fitting analysis $\left(\lambda_{\mathrm{ex}}=\right.$ $314 \mathrm{~nm}, \lambda_{\mathrm{em}}=586 \mathrm{~nm}$ ) according to the fluorescence titration experiments was created and displayed in Fig. 7b. As shown in Fig. 7b, the emission intensity at $586 \mathrm{~nm}$ show a good linear relationship with $R^{2}=0.9874$ over the range of $10 \mu \mathrm{M}$ to $50 \mu \mathrm{M}$, which indicating good sensing properties for PA. 

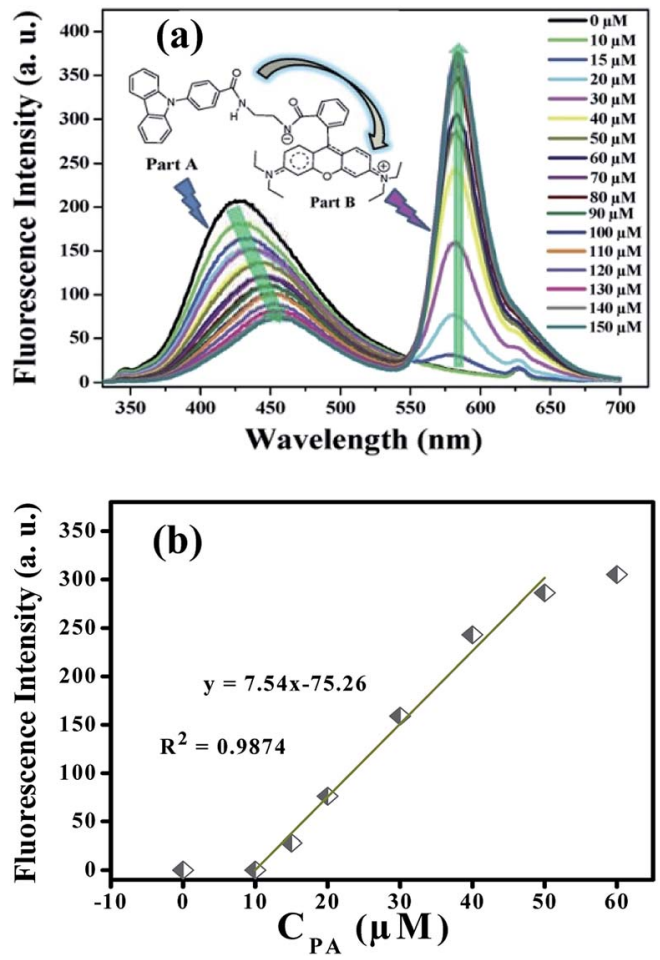

Fig. 7 (a) Fluorescence response of $L(20 \mu M)$ upon addition of PA from 10 to $150 \mu \mathrm{M}$ (inset, the proposed structure of the spiro-lactam ring-opening product); (b) linear fitting analysis $\left(\lambda_{\mathrm{ex}}=314 \mathrm{~nm}, \lambda_{\mathrm{em}}=\right.$ $586 \mathrm{~nm}$ ) of the fluorescence intensity at $586 \mathrm{~nm}$ versus the concentration of PA.

Interestingly, a fluorescence resonance energy transfer (FRET) phenomenon might occurred in the molecule of $\mathbf{L}$. The emission at $420 \mathrm{~nm}$ can be attributed to 4 -(9H-carbazol-9-yl) benzamide subunit (Part A of inset in Fig. 7a), which is a potential energy donor. After the addition of PA, the spirolactam ring opened and the rhodamine fluorophore (Part B of inset in Fig. 7a, the energy acceptor) formed simultaneously. A good overlap of the fluorescence spectrum of Part A (the energy donor unit) and the absorption spectrum of Part B (the energy acceptor unit) was observed (ESI, Part III Fig. S14†). In this case, the fluorescence emitted by Part A was absorbed by Part B, and used as the excitation light which induced the remarkable fluorescence at $586 \mathrm{~nm}$. A series of control experiments were performed under the identical conditions using $\mathrm{N}$-(rhodamineB)lactam-ethylenediamine and PA in ethanol, which also proved the existence of the intramolecular FRET effect (ESI, Part III Fig. S15 and S16 + ). In addition, this intramolecular FRET effect was further confirmed by the fluorescence decays assay $^{34-37}$ (ESI, Part III Fig. S17†)

\subsection{Binding mode investigation}

In order to reveal the stoichiometry between $\mathbf{L}$ and PA, mixture solutions of probe and PA with a total concentration of $200 \mu \mathrm{M}$ $(\mathbf{L}+\mathbf{P A})$ were used in the preparation of the Job's plot of complex $\left(\mathbf{L}+\right.$ PA) in ethanol ${ }^{38-40}$ and the results were displayed in Fig. 8a. Obviously, the plot revealed a $1: 1$ stoichiometry for PA and $\mathbf{L}$ (Fig. 8a). This binding mode was also verified by the Benesi-
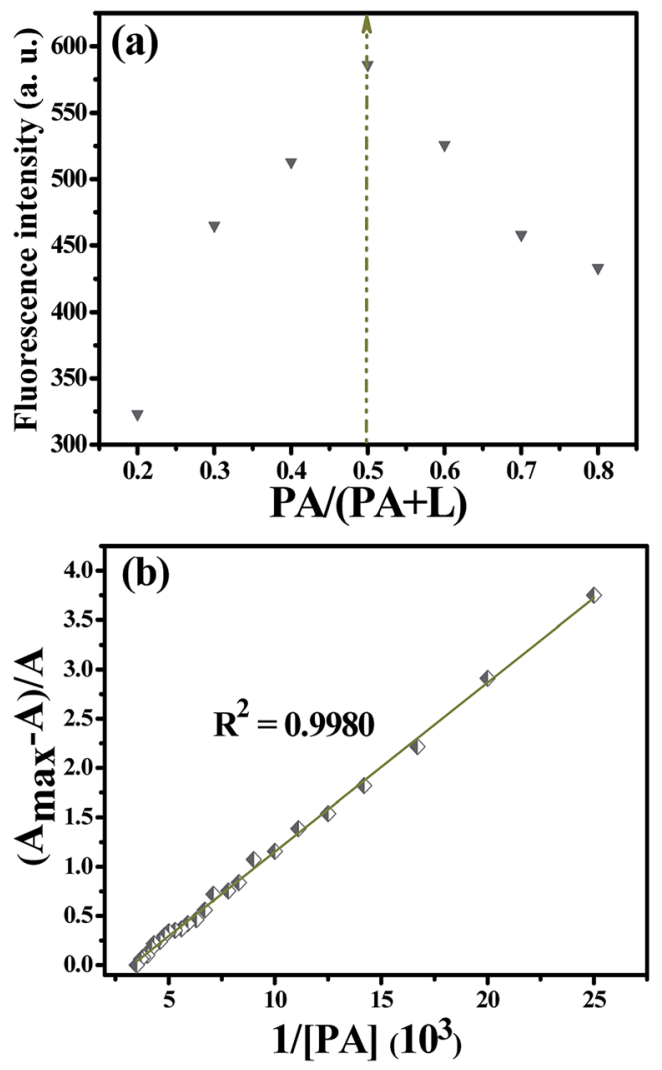

Fig. 8 (a) Job's plot of $L+P A$ complex in ethanol. $\left(\lambda_{\text {ex }}=500 \mathrm{~nm}, \lambda_{\mathrm{em}}=\right.$ $586 \mathrm{~nm}$, slits: $2.5 \mathrm{~nm} / 5 \mathrm{~nm}$ ); (b) Benesi-Hildebrand plot (absorbance at $560 \mathrm{~nm}$ ) of probe $\mathrm{L}$ assuming a $1: 1$ binding stoichiometry with PA.

Hildebrand plots, ${ }^{\mathbf{4 1 , 4 2}}$ which was obtained according to the colorimetric titration experiments (ESI, Part IV $\dagger$ ). The association constant $\left(K_{\mathrm{a}}\right)$ calculated according to the Benesi-Hildebrand plots (Fig. 8b) was $5834 \mathrm{~L} \mathrm{~mol}^{-1}$.

\subsection{Sensing mechanism}

${ }^{1} \mathrm{H}$ NMR spectroscopic titrations were performed in $\mathrm{CD}_{3} \mathrm{OD}$ to reveal the turn-on fluorescence mechanism and identify the possible binding position of PA (Fig. 9 and S19†). As depicted in Fig. 9, the peaks of $\mathrm{H}_{\mathrm{d}}$ and $\mathrm{H}_{\mathrm{e}}$ were clearly shifted downfield (0.36 ppm for $\mathrm{H}_{\mathrm{d}}$ and $0.07 \mathrm{ppm}$ for $\mathrm{H}_{\mathrm{e}}$ ), which indicated the positive electricity of $\mathrm{N}_{1}$ increased after the treatment with PA. Another remarkable change is the signals of $\mathrm{H}_{\mathrm{a}}, \mathrm{H}_{\mathrm{b}}$ and $\mathrm{H}_{\mathrm{c}}$ at 6.37-6.48 ppm, which almost disappeared in the presence of 1 equiv. of PA (shifted downfield from 6.37-6.48 ppm to 6.908.25 ppm, Fig. 9 and S19†). However, no significant change was observed with further increasing of PA from 2 equiv. to 10 equiv. revealing that a $1: 1$ binding stoichiometry was formed between $\mathbf{L}$ and PA (Fig. S19†). Furthermore, no obvious shift for $\mathrm{H}_{\mathrm{f}}$ was observed, which suggested there was no significant $\pi-\pi$ stacking or electron transfer between probe and PA. ${ }^{\mathbf{4 3 4 4}}$

The detection mechanism of this fluorescence "OFF-ON" type and "naked-eye" chemo-sensor for PA was further studied through theoretical calculations method (DFT calculation) ${ }^{45}$. Optimized geometries of the probe and PA as well as the energy changes are displayed in Fig. 10 It is clear that energy will be 

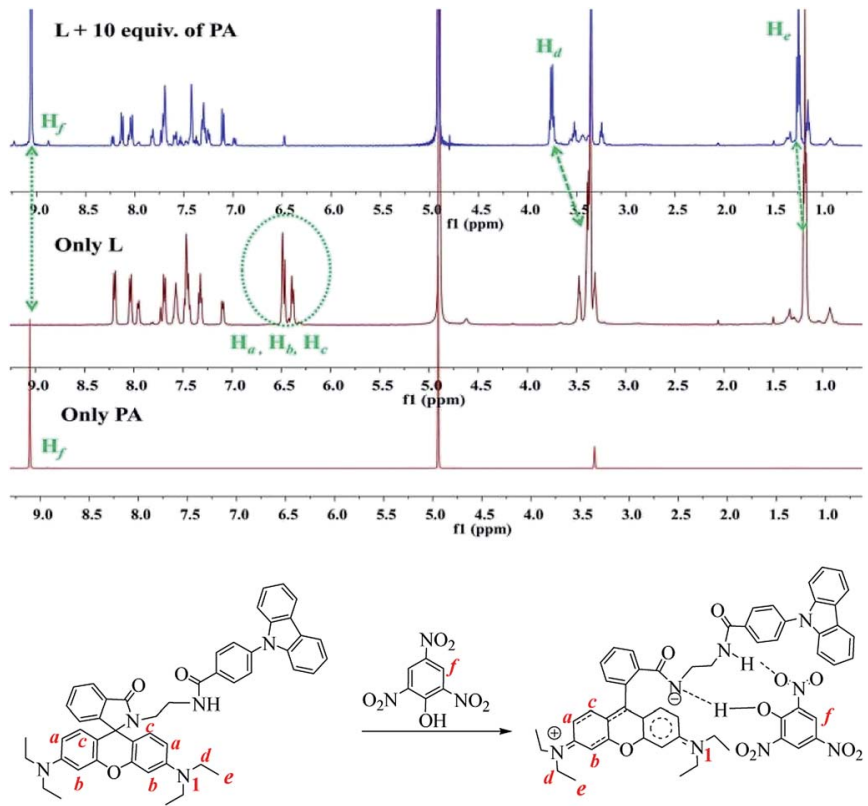

Fig. $9{ }^{1} \mathrm{HNMR}$ spectra of $L, P A$ and the mixture of $L+P A$ in $C D_{3} O D$.

released when the hydrogen bonded complex is formed $(\Delta E=$ $-17.9 \mathrm{~kJ} \mathrm{~mol}^{-1}$, Fig. 10 Path B). However, if the hydrogen completely transfers from PA $\left(\mathrm{H}_{\mathrm{a}}\right)$ to $\mathbf{L}\left(\mathrm{N}_{\mathrm{a}}\right)$ and form the ion pair, it would be a significantly endothermic process $(\Delta E=$ $+150.2 \mathrm{~kJ} \mathrm{~mol}^{-1}$, Fig. 10 Path A) which is not preferred.

The bond distances of $\mathrm{N}_{\mathrm{a}}-\mathrm{H}_{\mathrm{a}}$ and $\mathrm{O}_{\mathrm{a}}-\mathrm{H}_{\mathrm{a}}$ are $1.08 \AA$ and 1.28 $\AA$, respectively, which indicates that there is a strong attraction between $\mathbf{L}$ and PA linked by $\mathrm{H}_{\mathrm{a}}$. Another hydrogen bond between $\mathrm{O}_{\mathrm{b}}-\mathrm{H}_{\mathrm{h}}$ could also be observed as shown in Fig. 10 Path B.

With the above results in hand, a plausible sensing mechanism was proposed, as shown in Scheme 2. The spiro-lactam ring in probe $\mathbf{L}$ was opened after the addition of PA and hydrogen bonds formed between probe and PA. The formation of the delocalized xanthene motif would be response for the remarkable color changes (from colorless to pink) and fluorescence enhancement (intramolecular FRET phenomenon) of the sensor solution.

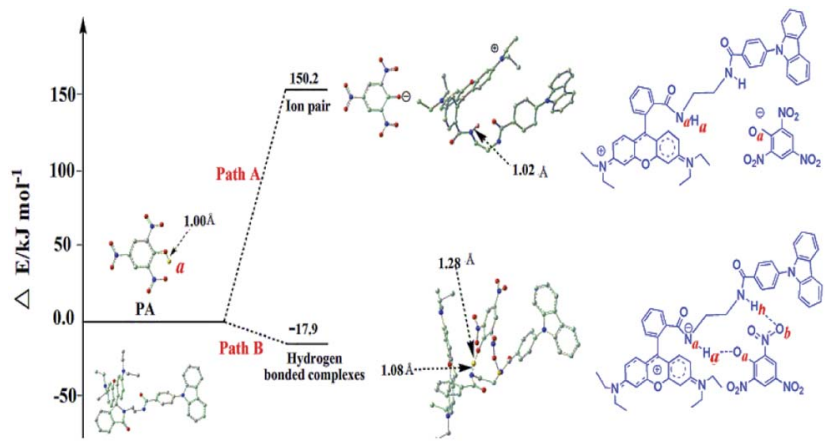

Fig. 10 DFT optimized structure and the energy changes. (The nitrogen atoms are showed in blue, oxygen in red, carbon in grey and hydrogen involved in the reaction is in yellow, the other hydrogen atoms have been omitted for clarity.)

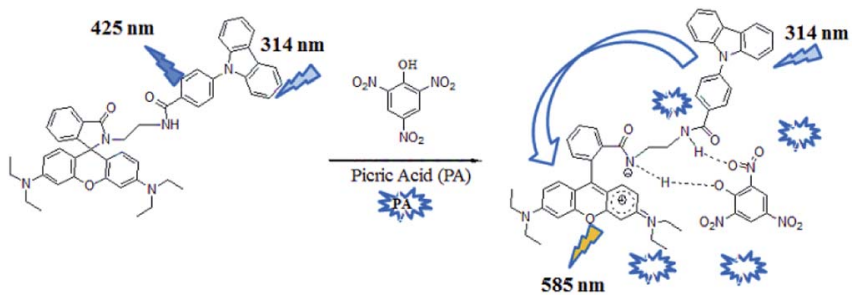

Scheme 2 A plausible reaction mechanism for the intramolecular FRET phenomenon.

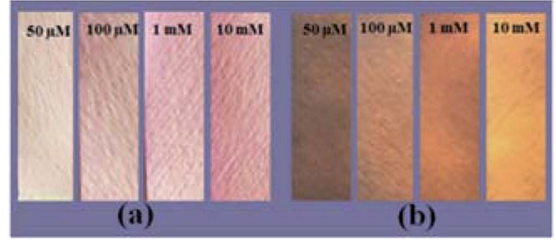

Fig. 11 Test strips for the detection of PA with the concentration from $50 \mu \mathrm{M}$ to $10 \mathrm{mM}$ under sunlight (a) and $365 \mathrm{~nm}$ UV light (b)

\subsection{Practical application}

In order to reveal the potential application of the as-synthesized probe, test strips were prepared. Filter papers were immersed in the probe stock solution and dried in air, then immersed into different concentration of PA solutions in water $(50 \mu \mathrm{M}, 100 \mu \mathrm{M}$, $1 \mathrm{mM}, 10 \mathrm{mM}$ ). As shown in Fig. 11, the pink color as well as the fluorescence intensity of the test papers intensified with the increasing PA concentrations. It is worth mention that the naked eye detectable concentration is about $50 \mu \mathrm{M}$.

\section{Conclusion}

In summary, a FRET based fluorescent and colorimetric chemoprobe for the specific detection of PA was revealed. The good selectivity and high sensitivity were demonstrated by fluorescence and colorimetric titration experiments, and an intermolecular FRET phenomenon was also observed and confirmed. The detection limit according to the colorimetric titration was found to be $820 \mathrm{nM}$, which indicating high detection sensitivity. Quantitative fluorescence and colorimetric titration revealed a $1: 1$ stoichiometry for PA and the probe. A plausible mechanism was postulated according to the binding mode studies, NMR analysis and the theoretical calculations. In addition, the notable features of this probe such as good selectivity and high sensitivity make it an useful indicator for PA detection.

\section{Conflicts of interest}

There are no conflicts to declare.

\section{Acknowledgements}

This work was supported by Natural Science Foundation of China (21663032), Natural Science Foundation of Shaanxi 
Province (2018JQ2079, 2018JQ2040), Scientific Research Program Funded by Shaanxi Provincial Education Department (17JK0869, 15JS121), Yan'an Science \&Technology Innovation Team (No. 2015CHTD-04), Startup Foundation for Docotors and Youth Science Foundation of Yan'an University (YDBK2015-06, YDBY2016-001, YDQ2017-14), National Undergraduate Training Programs for Innovation and Entrepreneurship (201710719005).

\section{References}

1 J. Shen, J. Zhang, Y. Zuo, L. Wang, X. Sun, J. Li, W. Han and R. He, J. Hazard. Mater., 2009, 163, 1199-1206.

2 V. Bhalla, A. Gupta, M. Kumar, D. S. Rao and S. K. Prasad, ACS Appl. Mater. Interfaces, 2013, 5(3), 672-679.

3 V. Bhalla, S. Kaur, V. Vij and M. Kumar, Inorg. Chem., 2013, 52(9), 4860-4865.

4 E. H. Volwiler, Ind. Eng. Chem., 1926, 18(12), 1336-1337.

5 P. G. Thorne and T. F. Jenkins, Field Anal. Chem. Technol., 1997, 1(3), 165-170.

6 Y. J. Tan, S. Z. Hu, G. L. Shen and R. Q. Yu, Anal. Chim. Acta, 2006, 570(2), 170-175.

7 B. Roy, A. K. Bar, B. Gole and P. S. Mukherjee, J. Org. Chem., 2013, 78(3), 1306-1310.

8 C. Behrend and K. Heesche-Wagner, Appl. Environ. Microbiol., 1999, 65(4), 1372-1377.

9 J. M. Sylvia, J. A. Janni, J. D. Klein and K. M. Spencer, Anal. Chem., 2000, 72(23), 5834-5840.

10 J. S. Caygill, F. Davis and S. P. Higson, Talanta, 2012, 88, 1429.

11 R. Hodyss and J. L. Beauchamp, Anal. Chem., 2005, 77(11), 3607-3610.

12 Y. B. Ding, Y. Y. Tang, W. H. Zhu and Y. S. Xie, Chem. Soc. Rev., 2015, 44, 1101-1112.

13 Y. B. Ding, W. H. Zhu and Y. S. Xie, Chem. Rev., 2017, 117(4), 2203-2256.

14 S. Sandhu, R. Kumar, P. Singh, A. Mahajan, M. Kaur and S. Kumar, ACS Appl. Mater. Interfaces, 2015, 7(19), 1049110500.

15 K. Maiti, A. K. Mahapatra, A. Gangopadhyay, R. Maji, S. Mondal, S. S. Ali, S. Das, R. Sarkar, P. Datta and D. Mandal, ACS Omega, 2017, 2(4), 1583-1593.

16 B. Gogoi and N. Sen Sarma, ACS Appl. Mater. Interfaces, 2015, 7(21), 11195-11202.

17 C. Wu, J. L. Zhao, X. K. Jiang, X. L. Ni, X. Zeng, C. Redshaw and T. Yamato, Anal. Chim. Acta, 2016, 936, 216-221.

18 J. F. Xiong, J. X. Li, G. Z. Mo, J. P. Huo, J. Y. Liu, X. Y. Chen and Z. Y. Wang, J. Org. Chem., 2014, 79(23), 11619-11630.

19 G. Sathiyan and P. Sakthivel, RSC Adv. , 2016, 6(108), 106705106715.

20 L. Cao, J. F. Xiong, Y. C. Wu, S. Ding, M. B. Li, F. Xie, Z. H. Ma and Z. Y. Wang, Chin. J. Org. Chem., 2016, 36, 2053-2074.

21 Y. C. Wu, S. H. Luo, L. Cao, K. Jiang, L. Y. Wang, J. C. Xie and Z. Y. Wang, Anal. Chim. Acta, 2017, 976, 74-83.

22 S. Nath, S. K. Pathak, B. Pradhan, R. K. Gupta, K. A. Reddy, G. Krishnamoorthy and A. S. Achalkumar, New J. Chem., 2018, 42(7), 5382-5394.
23 Y. Gao, Y. Qi, K. Zhao, Q. Wen, J. Shen, L. Qiu and W. Mou, Sens. Actuators, B, 2018, 257, 553-560.

24 J. R. Zhang, Y. Y. Yue, H. Q. Luo and N. B. Li, Analyst, 2016, 141(3), 1091-1097.

25 T. M. Geng, S. N. Ye, Y. Wang, H. Zhu, X. Wang and X. Liu, Talanta, 2017, 165, 282-288.

26 A. Buragohain, M. Yousufuddin, M. Sarma and S. Biswas, Cryst. Growth Des., 2016, 16(2), 842-851.

27 Y. H. Zhang, B. Li, H. P. Ma, L. M. Zhang and W. X. Zhang, J. Mater. Chem. C, 2017, 5(19), 4661-4669.

28 H. Guo, Y. Zhang, Z. Zheng, H. Lin and Y. Zhang, Talanta, 2017, 170, 146-151.

29 J. Ye, L. Zhao, R. F. Bogale, Y. Gao, X. Wang, X. Qian and G. Ning, Chem.-Eur. J., 2015, 21(5), 2029-2037.

30 Y. Deng, N. Chen, Q. Li, X. Wu, X. Huang, Z. Lin and Y. Zhao, Cryst. Growth Des., 2017, 17(6), 3170-3177.

31 B. Joarder, A. V. Desai, P. Samanta, S. Mukherjee and S. K. Ghosh, Chem.-Eur. J., 2015, 21(3), 965-969.

32 J. Liu and Y. Lu, Angew. Chem., 2007, 119, 7731-7734.

33 L. Peng, Q. Zhao, D. Wang, J. Zhai, P. Wang, S. Pang and T. Xie, Sens. Actuators, B, 2009, 136, 80-85.

34 K. E. Sapsford, L. Berti and I. L. Medintz, Angew. Chem., Int. Ed., 2006, 45, 4562-4588.

35 M. Tramier, M. Zahid, J. C. Mevel, M. J. Masse and M. Coppey-Moisan, Microsc. Res. Tech., 2006, 69(11), 933939.

36 P. I. Bastiaens and A. Squire, Trends Cell Biol., 1999, 9(2), 4852.

37 N. Andrews, M. C. Ramel, S. Kumar, Y. Alexandrov, D. J. Kelly, S. C. Warren, L. Kerry, N. Lockwood, A. Frolov, P. Frankel, L. Bugeon, J. McGinty, M. J. Dallman and P. M. W. French, J. Biophotonics, 2016, 9(4), 414-424.

38 Q. H. You, P. S. Chan, W. H. Chan, S. C. Hau, A. W. Lee, N. K. Mak and R. N. Wong, RSC Adv., 2012, 2(29), 1107811083.

39 L. Zhang, J. Fan and X. Peng, Spectrochim. Acta, Part A, 2009, 73(2), 398-402.

40 A. Kumar and N. Ahmed, Ind. Eng. Chem. Res., 2017, 56(22), 6358-6368.

41 M. Suresh, A. K. Mandal, S. Saha, E. Suresh, A. Mandoli, R. Di Liddo and A. Das, Org. Lett., 2010, 12(23), 5406-5409.

42 B. Chowdhury, S. Khata, R. Dutta, S. Chakraborty and P. Ghosh, Inorg. Chem., 2014, 53(15), 8061-8070.

43 A. Kumar, A. Pandith and H. S. Kim, Sens. Actuators, B, 2016, 231, 293-301.

44 D. C. Santra, M. K. Bera, P. K. Sukul and S. Malik, Chem.-Eur. J., 2016, 22(6), 2012-2019.

45 M. J. Frisch, G. W. Trucks, H. B. Schlegel, G. E. Scuseria, M. A. Robb, J. R. Cheeseman, G. Scalmani, V. Barone, B. Mennucci, G. A. Petersson, H. Nakatsuji, M. Caricato, X. Li, H. P. Hratchian, A. F. Izmaylov, J. Bloino, G. Zheng, J. L. Sonnenberg, M. Hada, M. Ehara, K. Toyota, R. Fukuda, J. Hasegawa, M. Ishida, T. Nakajima, Y. Honda, O. Kitao, H. Nakai, T. Vreven, J. A. Montgomery Jr, J. E. Peralta, F. Ogliaro, M. Bearpark, J. J. Heyd, E. Brothers, K. N. Kudin, V. N. Staroverov, R. Kobayashi, J. Normand, K. Raghavachari, A. Rendell, J. C. Burant, 
S. S. Iyengar, J. Tomasi, M. Cossi, N. Rega, J. M. Millam, M. Klene, J. E. Knox, J. B. Cross, V. Bakken, C. Adamo, J. Jaramillo, R. Gomperts, R. E. Stratmann, O. Yazyev, A. J. Austin, R. Cammi, C. Pomelli, J. W. Ochterski, R. L. Martin, K. Morokuma, V. G. Zakrzewski, G. A. Voth,
P. Salvador, J. J. Dannenberg, S. Dapprich, A. D. Daniels, Ö. Farkas, J. B. Foresman, J. V. Ortiz, J. Cioslowski and D. J. Fox, Gaussian 09, Revision A.1, Gaussian Inc, Wallingford CT, USA, 2009. 